\title{
Suppliers step in to manage chemical use
}

\section{Jim Giles}

The consumption of chemicals in some US industries is being reduced by making suppliers fully responsible for the use and recycling of their products, says a report out next week.

The Chemical Strategies Partnership (CSP), a San Franciscobased organization that promotes this new way of working, has conducted a survey of the approach's spread. It says that the industry has begun a long-term shift away from just selling chemicals towards arrangements in which suppliers are far more actively involved in managing the use of their products. The trend is likely to lead to better environmental stewardship, the CSP says.

The approach is being adopted by large industrial customers in the United States. Rather than just buying paint, for example, car manufacturers such as General Motors are bringing suppliers into their assembly plants to manage the entire painting process.

"The supplier gets paid per car body coated," explains Kevin Swift, an economist at the American Chemistry Council, an industry body in Arlington, Virginia. "So the incentive is for them to cut down on paint."

The CSP's survey, scheduled for publication on 14 September, says that the practice is booming: the market for chemical-manage-

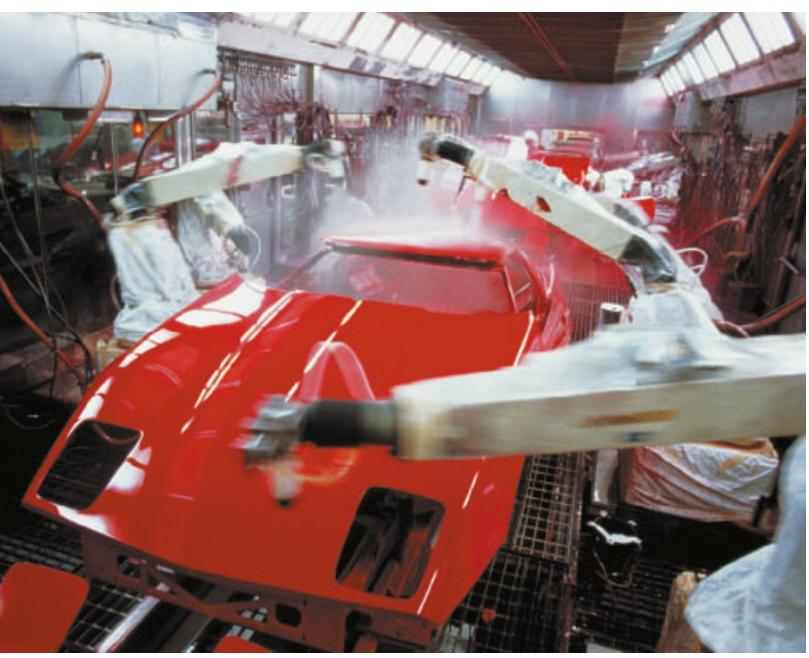

Net paint: chemical suppliers' advice has reduced car factory emissions.

says. Now it uses about half as many chemicals, sourced from just five firms. "In the first year of implementation we saw $25 \%$ savings," says Knoblock. "And all of our management programmes have reduced emissions of chemicals."

Tom Bierma, an environmental health expert at Illinois State University in Normal, says that research laboratories could eventually benefit from the inventory, safety and training services now being offered by suppliers, even though the amount of chemicals they use is relatively small.

This is backed up by CSP case studies of chemical management in US labs. In a study at the Stanford Linear Accelerator Center in ment services has grown by about half since 2000 and is now worth US\$1.2 billion. Car makers lead the way, with $80 \%$ of the industry outsourcing management of chemicals. Aerospace and electronic firms are also using the approach. And the report suggests that, in the long term, academic labs could buy some of their chemicals this way.

General Motors has benefited from the approach, says Michael Knoblock, an environmental services manager at the company's offices in Pontiac, Michigan. In the 1980s, the firm used 10,000 different chemical companies to supply it with the 150,000 or so different substances it needed for its business, he
California, it suggested that the lab could save money by coordinating its purchasing, which is currently spread across many individuals in different departments. The CSP also says suppliers could help labs to design more environmentally friendly means of dealing with chemical waste.

The CSP wants to export its approach and there are signs that European companies may be ready to take it up. Knoblock, for example, says that he expects the first chemicals-management programme at a General Motors plant in Europe to be up and running within a year.

www.chemicalstrategies.org

\section{China increases share of global scientific publications}

David Cyranoski

China's scientific growth is keeping up with its meteoric economic rise, according to figures released last week. But the growth seems to vary widely between fields and the quality of the work may be lagging in some of them.

Between 1981 and 2003, China clocked a 20-fold increase in its publications in international scientific journals (see graph), reports Science Watch, a newsletter tracking trends in scientific activity, published by Philadelphia-based Thomson ISI.

Although China publishes only half as many papers as Japan, it is pulling away from other nations in the region, such as South Korea, Taiwan and Singapore. China now accounts for over $5 \%$ of the world's scientific publications.

Papers with authors affiliated to Chinese institutions now account for $10 \%$ of the literature in materials science, and for $8 \%$ of that in mathematics and physics.

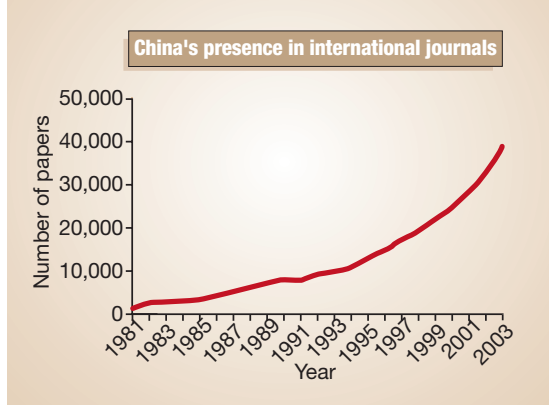

Ron Shen, a materials scientist at the University of California, Berkeley, who is originally from Shanghai, says that China has strong historical foundations in metallurgy. He says its interest in materials science has accelerated with access to better equipment.

Shen notes, however, that papers in many fields, including physics, chemistry and geosciences, still have low 'average impact factors'. The impact factor is a rough measure of how influential a paper is.
"Chinese researchers are good in analytical and technical skills," he says, "but perhaps weaker on reasoning and interpretation."

China remains one of the smaller players in the life sciences, with its share of total publications ranging from $\mathbf{0 . 8} \%$ in immunology to $2 \%$ in plant science, Science Watch finds. And Mu-Ming Poo, who heads the Institute of Neuroscience in Shanghai, says that some of the overall growth in the nation's scientific profile can be attributed to the thousands of papers from labs in the United States that are co-authored by visiting Chinese researchers and students who maintain affiliations in their homeland.

Chinese authors do account for an increasing number of the world's most influential papers, finds Science Watch. But to get ahead, Shen says, China needs to assert itself as a leader and not a follower. "It is still very much influenced by the outside world," he says, "so it follows the research trends of the West very closely." 